\title{
Prescription medication cost, insurance coverage, and cost-related nonadherence among people with spinal cord injury in Canada
}

\author{
Shikha Gupta $\mathbb{D}^{1} \cdot$ Mary Ann McColl ${ }^{1} \cdot$ Karen Smith $^{2} \cdot$ Sara J. T. Guilcher $\mathbb{1}^{3}$
}

Received: 4 September 2019 / Revised: 9 December 2019 / Accepted: 11 December 2019 / Published online: 3 January 2020

(c) The Author(s), under exclusive licence to International Spinal Cord Society 2020

\begin{abstract}
Study design Observational cross-sectional study.

Objectives To describe the most common prescription medications used and the extent of out-of-pocket cost, insurance coverage, and cost-related nonadherence (CRNA) for those medications by people with spinal cord injury (SCI) in Canada. Setting Community in Canada.

Methods It was an observational study wherein data were collected through a cross-sectional online survey from individuals living with an SCI in Canada. We used descriptive statistics to describe the extent of drug cost, insurance coverage and CRNA among study sample, and analytical statistics to find association of CRNA with sociodemographic, injury-related and medication-related characteristics of the sample.

Results Individuals with an SCI $(n=160)$ used an average of five medications and spent a median of $\$ 49$ (interquartile range: \$234.75) per month on their medications. More than $90 \%$ of participants had some form of drug insurance, though $37 \%$ reported CRNA. The most common medications that were forgone due to cost included opioids, antidepressants, and drugs for genitourinary and muscular spasms. Individuals with paraplegia and nontraumatic SCI had higher drug costs, though injury-related characteristics did not influence CRNA. Sex, monthly drug expenditure, and monthly additional healthcare costs were significantly associated with CRNA.

Conclusions People with SCIs are at risk of experiencing CRNA to their prescription medications despite having insurance coverage. Decision makers for the national pharmacare in Canada should account for their concerns judiciously.
\end{abstract}

\section{Introduction}

The cost of living with a spinal cord injury (SCI) has been estimated between 1.47 and 3.03 million Canadian dollars in a lifetime $[1,2]$. Secondary complications and health conditions make people with SCI high users of medications in comparison to the general population [3, 4]. Prescription medications now constitute one of the topmost drivers of healthcare costs in Canada. In 2018, pharmaceutical drugs

Shikha Gupta

shikha.gupta@queensu.ca

1 School of Rehabilitation Therapy, Queen's University, Kingston, ON, Canada

2 Department of Physical Medicine and Rehabilitation, School of Medicine, Queen's University, Kingston, ON, Canada

3 Leslie Dan Faculty of Pharmacy, University of Toronto, Toronto, ON, Canada represented the second highest expenditure for healthcare (16\%, after hospitals, 28\%), and expenditure growth on drugs outpaced that for hospitals and physicians [5].

In Canada, prescription drug coverage is not included in the universal health insurance scheme. Instead, there are five possible ways that people pay for prescription medication: private drug insurance, employer-sponsored insurance, provincial drug benefits (for adults $>65$ years, people on social assistance, or those with catastrophic drug costs), inclusion on a family member's plan, or out of pocket. For all of the insurance options, the extent of coverage varies, and individuals may pay premiums, copayments, or deductibles. Out-ofpocket drug costs for Canadians have been estimated between $\$ 0$ and $\$ 2500$ a year, depending on the medication costs, insurance, age, employment, and income [6, 7].

In the absence of universal pharmacare, many people choose to forego their medications due to cost, a phenomenon called cost-related nonadherence (CRNA) [8]. CRNA has been observed among chronically ill populations, and those with lower income, irregular employment, lack drug 
insurance, and high drug costs $[9,10]$. No studies were found that explored this phenomenon among people with SCIs, who are high users of medication, in addition to other healthcare services due to their disability. Within the SCIspecific literature, studies so far have explored medication use with respect to individuals' demographic and injuryrelated characteristics, or the intensity and prevalence of adverse drug reactions and polypharmacy within the SCI population $[11,12]$.

This study aimed to answer the following questions:

(a) What are the most common medications used by people with SCIs in Canada?

(b) What are the costs of different types of medications and to what extent are they typically covered by insurance?

(c) To what extent is CRNA practiced by people with an SCI in Canada, and who is more likely to engage in CRNA?

\section{Methods}

\section{Study design and data collection}

It was an observational cross-sectional study [13]. Data were collected through an online survey. A questionnaire was developed and validated through pilot testing, expert consultation (MAM, SJTG, and KS), and testing its alignment with the CRNA component of the Canadian Community Health Survey of 2016. The questionnaire had 35 questions, including branching and adaptive questioning. It was pilot tested with four participants for the sensitivity of its items, language, content, appearance, and functionality. Participants were reminded to assemble their medications and other necessary medical records before starting to answer the survey. "Qualtrics"T"-web-based survey software-was used for data collection [14].

\section{Sample and setting}

The sample for the study comprised individuals living in the community with an SCI in Canada. An SCI was defined as an injury that occurs when trauma (such as a fall, vehicle accident, act of violence) or disease (such as a motor neuron disease, tumor, infection, myelopathy, vascular, toxic, metabolic condition, or a developmental disorder) damages the spinal cord, resulting in partial or complete paralysis [15]. The proposed sample size for the study was between 120 and 140 participants, which was calculated based on a formula suggested for survey-based studies [16]. The inclusion criteria included individuals with an SCI with the age of 18 years or more, living in Canada, and were prescribed one or more medications at the time of the survey. Individuals living in a nursing home or hospitalized at the time of the survey were excluded. Approximately 85,000 people in the community live with an SCI in Canada [15]. The sample of our study was reasonably congruent with the sample of a recent national study of Canadians with an SCI [17], except that our sample included more females. In total, 189 individuals responded to the online survey, out of which 160 were included in the final analyses, based on the completion of their responses (completion rate: $85 \%)$. The duplicate or fake entries $(n=12)$ were identified through the log files and were excluded.

\section{Recruitment}

Participants were recruited over 6 months (May-October 2018) with the help of community-based organizations. We contacted five national organizations working with individuals with traumatic or nontraumatic SCIs in Canada. Most of these organizations have a client database and a network of local chapters to serve their clients in different locations or cities. These local chapters used their regular email listserv or a newsletter to share the study information with their clients. A few organizations posted the study information on their website or social media page too. The study protocol was reviewed and approved before it was disseminated among their clients. To ensure that our recruitment does not exclude people who do not use the services of these organizations, we posted study information at local outpatient clinics, hospitals, and pharmacies with the help of a representative from the local chapters or members of our research team. The posted information had a QR code that participants could scan to go to the survey link. Participants were offered a $\$ 5$ gift card for their participation.

\section{Study variables}

To find independent factors associated with CRNA, we divided the study variables into dependent and independent variables as follows.

\section{Dependent variable}

CRNA CRNA was our primary outcome variable that was measured by asking participants if they have ever taken less of one or more of their medications than prescribed because of cost in the last 12 months (yes/no). This question was asked for each prescription they reported on the survey.

\section{Independent variables}

Medication use We asked our participants to list all medications prescribed to them in the last 12 months. A 
prescription medication was defined as a pharmaceutical drug that legally requires a medical prescription to be dispensed. The reported drugs were classified under 14 categories as per the World Health Organization's Anatomical Therapeutic Chemical (WHO-ATC) classification system [18]. To classify the drugs reported in our survey, the first author (SG) located the reported drug name on the ATC classification guide and categorized it as per its therapeutic subgroup (levels 1 and 2). The drugs that belonged to different ATC categories (example: anti-inflammatory drugs) were categorized as per their indicated use reported by the participants. Any drug names (e.g., new drugs) that were not on the WHO list were classified based on the information available through an online database (drugbank.ca, version 5.1.2, released 2018-12-20) [19]. The third author (KS), who is a medical physiatrist, confirmed the accuracy of the prescribed medication classification as per the standard of practice or recommended use.

Drug coverage Participants were asked the type of drug insurance they have for every medication they reported on the survey. The response options included provincial drug benefits, private drug insurance, employer-based insurance, family-based insurance, or no insurance.

Medication costs This involved information on monthly costs directly borne by the participants for their drugs (after insurance coverage) such as in the form of copay, deductibles, or pharmacist dispensing fee (open-ended). All amounts were collected in 2018 Canadian dollars. Participants listed these costs for every medication they reported on the survey.

Sociodemographic and injury-related variables These included age, sex, employment status, province, personal income, cause of injury, level of injury, the extent of the injury, and time since injury (open-ended).

Additional healthcare costs We asked participants to estimate the amount they spend every month on their other healthcare needs or supplies such as catheters, wheelchairs, special diet, and skincare supplies (open-ended).

\section{Analyses and reporting}

Descriptive statistics were used to present sociodemographic, injury-related information, and the type and number of medications reported by the participants. Analysis of variance (ANOVA), $\chi^{2}$, and $t$-tests were conducted to analyze drug costs, insurance coverage, and CRNA with respect to participants' sociodemographic, injury-related, and medication-related characteristics. Binomial logistic regression was used to determine independent factors associated with CRNA among study sample. Statistical Package of Social Sciences (IBM SPSS V.24) was used for data analysis.

\section{Results}

\section{Sample characteristics}

The average age of our sample was $47( \pm 13)$ years; $56 \%$ were females; $62 \%$ lived in Ontario, and $40 \%$ were receiving disability benefits as their primary source of income. Of the total sample, $58 \%$ had an SCI due to a traumatic cause; more than $60 \%$ had paraplegia and incomplete injuries. One-third (33\%) of the sample had cervical injury, more than half $(52 \%)$ had a thoracic level injury, and rest $(15 \%)$ had an injury at or below lumbosacral level. Mean time since injury was $18 \pm 13$ years.

\section{Prescription medication use, cost, and insurance coverage}

Medication use A total of 832 prescriptions were reported by our sample, representing 296 different medications. On average, participants used $5.47( \pm 3.03)$ medications and $48 \%$ of participants used $>5$ medications concurrently (Table 1). The most common medications belonged to the category of the central nervous system (38\%) that comprised antidepressants, anticonvulsants, anxiolytics, antipsychotics, and opioids, generally prescribed for neuropathic pain, depression, anxiety, sleep, or moodrelated disorders. Other most commonly prescribed drugs included antibiotics (11\%) for bladder infections, drugs for the cardiovascular system (8\%), skeletal muscle relaxants $(9 \%)$, and antispasmodic or anticholinergic drugs for genitourinary spasms $(6 \%)$.

Medication cost and insurance coverage To determine the specific drug classes with high out-of-pocket cost and lower coverage, we chose the top eight therapeutic drug classes most commonly prescribed to our sample (Table 2). These drugs constituted almost $80 \%$ of the total medications prescribed to our sample. Table 2 lists the costs of different types of medications and the extent they are typically covered by insurance. Within these eight drug classes, opioids had the highest cost, and lowest insurance coverage. Following this, anticonvulsants, skeletal muscle relaxants, and antidepressants had the highest cost for patients, whereas antibiotics, drugs for alimentary tract and metabolism, and genitourinary spasms had lowest insurance coverage.

Overall, individuals with an SCI spent a median of \$49 (interquartile range: \$234.75). The majority of the participants (92\%) had some form of drug insurance to help cover 
Table 1 Medication profile of study sample of community-dwelling persons with spinal cord injury $(n=160)$.

\begin{tabular}{|c|c|c|c|}
\hline Code & Drug therapeutic class & $N=832(100 \%)$ & No. of different medications \\
\hline \multirow[t]{8}{*}{$\mathrm{N}$} & Nervous system & $309(37.5 \%)$ & 98 \\
\hline & - Anticonvulsants/anxiolytics/antipsychotics & 115 & 29 \\
\hline & - Hypnotics/sedatives & 12 & 5 \\
\hline & - Antidepressants & 76 & 23 \\
\hline & - CNS stimulants & 10 & 5 \\
\hline & - Opioids & 85 & 27 \\
\hline & - Migraine meds & 6 & 5 \\
\hline & - Neuroprotective agent & 5 & 4 \\
\hline \multirow[t]{4}{*}{ M } & Musculoskeletal system & $137(16.5 \%)$ & 26 \\
\hline & - NSAIDs & 31 & 13 \\
\hline & - Skeletal muscle relaxants & 95 & 10 \\
\hline & • B-phosphonates & 11 & 3 \\
\hline \multirow[t]{3}{*}{$\mathrm{J}$} & Anti-infectives for systemic use & $92(11.1 \%)$ & 26 \\
\hline & - Antibiotics & 89 & 24 \\
\hline & - Antiviral & 3 & 2 \\
\hline \multirow[t]{6}{*}{ A } & Alimentary tract and metabolism & $76(9.1 \%)$ & 32 \\
\hline & - Proton pump inhibitors, bile acid sequestrants & 29 & 8 \\
\hline & - Laxatives or stool softeners & 18 & 7 \\
\hline & - Antihyperglycemic & 15 & 7 \\
\hline & - Anti-inflammatory & 10 & 7 \\
\hline & - Anti-allergic & 4 & 3 \\
\hline \multirow[t]{5}{*}{$\mathrm{C}$} & Cardiovascular system & $70(8.4 \%)$ & 42 \\
\hline & - Antihypertensives & 13 & 7 \\
\hline & - Diuretics & 6 & 4 \\
\hline & - Anticoagulants/antilipemic & 30 & 15 \\
\hline & - ACE inhibitors/B-blockers & 21 & 16 \\
\hline \multirow[t]{3}{*}{ G } & Genitourinary system and sex hormones & $62(7.5 \%)$ & 28 \\
\hline & - Sexual hormones and birth control & 11 & 9 \\
\hline & - Antispasmodic or anticholinergic & 51 & 19 \\
\hline \multirow[t]{4}{*}{$\mathrm{L}$} & Antineoplastic and immunomodulating agents & $26(3.1 \%)$ & 12 \\
\hline & - Antineoplastic & 3 & 2 \\
\hline & - Immunosuppressants/modulators & 20 & 9 \\
\hline & - Beta-interferon & 3 & 1 \\
\hline \multirow[t]{2}{*}{$\mathrm{R}$} & Respiratory system & & \\
\hline & - Bronchodilators & $14(1.7 \%)$ & 8 \\
\hline \multirow[t]{2}{*}{$\mathrm{H}$} & Systemic hormonal preparations, excluding sex & insulins & \\
\hline & - Thyroid therapy & $12(1.4 \%)$ & 4 \\
\hline $\mathrm{V}$ & Various & $10(1.2 \%)$ & 3 \\
\hline \multirow[t]{2}{*}{ B } & Blood and blood forming organs & & \\
\hline & - Antithrombotic/antihemorrhagics & $9(1.1 \%)$ & 7 \\
\hline \multirow[t]{2}{*}{$\mathrm{D}$} & Dermatologicals & & \\
\hline & - Antifungal & $7(0.8 \%)$ & 6 \\
\hline \multirow[t]{2}{*}{$\mathrm{P}$} & Antiparasitic products, insecticides and repellen & & \\
\hline & - Antimalarials & $5(0.6 \%)$ & 2 \\
\hline S & Sensory organs & $3(0.4 \%)$ & 2 \\
\hline
\end{tabular}

The number of medications belonging to different drug classes were accumulated for all patients 
Table 2 Out-of-pocket costs, drug insurance coverage and prevalence of CRNA for most common medications used among study sample of community-dwelling persons with spinal cord injury $(n=160)$.

\begin{tabular}{|c|c|c|c|c|}
\hline Top eight drug classes & $N$ & $\begin{array}{l}\text { Monthly cost, mean } \\
\pm \text { s.d. (range) }\end{array}$ & $\begin{array}{l}\text { Insurance } \\
\text { availability, } n(\%)\end{array}$ & $\begin{array}{l}\text { Prevalence of } \\
\text { CRNA, } n(\%)\end{array}$ \\
\hline $\begin{array}{l}\text { 1. Anticonvulsants/anxiolytics/ } \\
\text { antipsychotics }\end{array}$ & 115 & $38.90 \pm 91.31(585)$ & $95(82.6)$ & $9(7.8)$ \\
\hline 2. Skeletal muscle relaxants & 95 & $24.78 \pm 94.51(900)$ & $86(90.5)$ & $11(11.6)$ \\
\hline 3. Antibiotics & 89 & $13.02 \pm 20.80(100)$ & $63(70.8)$ & $7(7.9)$ \\
\hline 4. Opioids & 85 & $54.67 \pm 97.32(550)$ & $55(64.7)$ & $26(30.6)$ \\
\hline 5. Antidepressants & 76 & $23.11 \pm 69.11(585)$ & $65(85.5)$ & $12(15.8)$ \\
\hline $\begin{array}{l}\text { 6. Drugs for alimentary tract and } \\
\text { metabolism }\end{array}$ & 76 & $11.38 \pm 21.03(125)$ & $62(81.6)$ & $7(9.2)$ \\
\hline 7. Cardiovascular drugs & 70 & $10.25 \pm 13.40(59)$ & $58(82.9)$ & $5(7.1)$ \\
\hline 8. Drugs for genitourinary spasms & 51 & $19.91 \pm 28.75(144)$ & $41(80.4)$ & $9(17.6)$ \\
\hline
\end{tabular}

the cost of the medications (provincial drug benefit: $48 \%$; employer-based insurance: $14 \%$; private insurance: $50 \%$; family-based insurance: $11 \%$; no insurance: $9 \%$ ). Also note that these numbers do not add up to 100 as 36 participants (22.5\% of total sample) had more than one type of drug insurance. Within the group of participants who had some form of drug insurance, $45 \%$ paid less than $\$ 5$ a month and $12 \%$ paid more than $\$ 100$ a month (\$6-\$20/month: $18 \%$; \$21-\$50/month: $17 \%$; \$51-\$100/month: $8 \%$ ).

Although in our sample, females and individuals between 26 and 64 years of age had higher drug costs and lower insurance coverage, these were not statistically significant than males and individuals in other age groups. Similarly, those who were employed full-time; and earning $>\$ 60,000 /$ year had the highest drug costs and better drug coverage, though these were statistically insignificant in comparison with other groups. With respect to an SCI-related characteristics, individuals with nontraumatic SCI incurred significantly higher cost on their drugs ( $t: 2.26$; $p$ : 0.026), despite having higher insurance coverage, in comparison to those with traumatic SCI. Individuals with paraplegia had significantly higher drug costs $(t: 2.12 ; p: 0.035)$, though their drug insurance did not differ significantly from those with tetraplegia. The completeness of injury and time since injury did not have any significant influence on prescription drug cost or coverage among the study sample.

\section{The extent of CRNA among the study population and its association with various factors}

Extent of CRNA Among the total sample, 59 (37\%) individuals reported CRNA (Table 3 ). Within these individuals, $28(48 \%)$ individuals reported CRNA for one medication, while $31(52 \%)$ reported CRNA for two or more medications. The most common drugs that were forgone due to high costs were opioids, antidepressants, and drugs for genitourinary and muscular spasms (Table 2). Table 3 presents the distribution and extent of CRNA among the study sample. Concerning participants' sociodemographic and SCI-specific characteristics, we found that females $\left(\chi^{2}\right.$ : 8.47; $p$ : 0.004), individuals between 26 and 64 years $\left(\chi^{2}: 10.72 ; p: 0.005\right)$, and those with nontraumatic SCI $\left(\chi^{2}: 7.58 ; p: 0.006\right)$ were significantly more likely to experience CRNA than other groups. Individuals who reported CRNA spent an average of $\$ 398$ per month on their medications in comparison to $\$ 80$ spent by those without CRNA ( $t$ : 4.90; $p<0.001)$. Those who reported CRNA spent an average of $\$ 674$ per month on their additional healthcare needs in comparison to $\$ 241$ paid by those without CRNA $(t: 3.91 ; p<0.001)$. Having drug insurance or not, and the number of medications used did not differ significantly between CRNA and non-CRNA group.

Independent factors associated with CRNA All of the above variables that showed significant association with CRNA during bivariate analyses were tested for their independent effect in the regression model (Table 4). The null hypothesis for logistic regression analyses was that there are no associations between CRNA and participant's age, sex, cause of injury, out-of-pocket costs on medications, and additional healthcare costs. The model was built through a backward elimination method. The final model revealed that sex, monthly drug expenditure and monthly additional healthcare costs were significantly associated with CRNA among study sample. The results indicated that:

- Females were three times more likely than males to face CRNA after controlling for other factors, i.e., when they had similar monthly drug costs and additional healthcare costs.

- With every $\$ 50$ increase in the monthly expenditure on drugs, the risk of CRNA increased to $28 \%$ after other factors were controlled. In other words, monthly drug expenditure of $\$ 81$ increased the risk of facing CRNA among individuals with SCIs by $50 \%$.

- With every $\$ 50$ increase in the additional healthcare costs, the risk of CRNA increased to $5 \%$ after other factors were controlled. In other words, a monthly 
Table 3 Distribution and extent of CRNA among study sample of community-dwelling persons with spinal cord injury $(n=160)$.

\begin{tabular}{llll}
\hline Total & Extent of & Test statistic, \\
sample, & CRNA, & significance \\
$n(\%)$ & $n(\%)$ & $\begin{array}{l}\text { level, and } \\
\text { effect size }\end{array}$ \\
\hline
\end{tabular}

Total sample $\quad 160(100) \quad 59(37)$

CRNA w.r.t. sociodemographic characteristics of study sample

Gender

- Males

- Females

$70(43.75)$

$17(24.3)$

$\chi^{2}: 8.47$

Age (years)

$90(56.25)$

$42(46.7)$

$p: 0.004^{\mathrm{a}}$

$-<25$

$$
12(7.5)
$$

$3(25)$

$V: 0.23$

- 26-64

$129(80.6)$

55 (42.6)

$\chi^{2}: 10.72$

$\cdot>65$

19 (11.9)

1 (5.3)

$p: 0.005^{\mathrm{a}}$

Employment status

- Full-time

$$
33 \text { (20.6) }
$$

$9(27.3)$

V: 0.25

- Part-time

$108(67.5)$

$44(40.7)$

$\chi^{2}: 2.22$

- Unemployed

19 (11.9)

$6(31.6)$

p: 0.328

Annual income

- $<20,000$

$$
66 \text { (41.3) }
$$

26 (39.4)

- 20,001-39,999

$56(35.0)$

$24(42.9)$

$\chi^{2}: 4.17$

- 40,000-59,999

$22(13.8)$

$6(27.3)$

$p: 0.244$

- $>60,000$

$16(10.0)$

$3(18.8)$

$V: 0.16$

CRNA w.r.t. injury-related characteristics of study sample

Cause of injury

- Traumatic

$$
\begin{aligned}
& 93(58) \\
& 67(42)
\end{aligned}
$$

$26(28.0)$

$\chi^{2}: 7.58$

- Nontraumatic

$33(49.3)$

$p: 0.006^{\mathrm{a}}$

$V: 0.21$

Level of injury

- Tetraplegia

- Paraplegia

$$
\begin{aligned}
& 53(33) \\
& 107(67)
\end{aligned}
$$$$
14 \text { (26.4) }
$$$$
\chi^{2}: 3.72
$$

$45(42.1)$

p: 0.054

$V: 0.30$

Extent of injury

$\begin{array}{llll}\text { - Complete } & 59(37) & 20(33.9) & \chi^{2}: 0.35 \\ \text { - Incomplete } & 101(63) & 39(38.6) & \begin{array}{l}p: 0.551 \\ V: 0.09\end{array} \\ & & & \\ \text { Time since injury } & & & \\ \text { - }<5 \text { years } & 35(21.9) & 11(31.4) & \chi^{2}: 0.82 \\ \text { - 6-19 years } & 59(36.9) & 24(40.7) & p: 0.664 \\ \text { - }>20 \text { years } & 66(41.3) & 24(36.4) & V: 0.07\end{array}$

CRNA w.r.t. medication-related characteristics of study sample

Number of $5.47( \pm 3.03)$

medications used

- CRNA group

- Non-CRNA group

$\begin{array}{ll}\text { Monthly } & 49(0.00, \\ \text { expenditure on } & 234.75) \\ \text { drugs }^{\mathrm{a}} & \end{array}$

Table 3 (continued)

\begin{tabular}{llll}
\hline & $\begin{array}{l}\text { Total } \\
\text { sample, } \\
n(\%)\end{array}$ & $\begin{array}{l}\text { Extent of } \\
\text { CRNA, } \\
n(\%)\end{array}$ & $\begin{array}{l}\text { Test statistic, } \\
\text { significance } \\
\text { level, and } \\
\text { effect size }\end{array}$ \\
\hline - CRNA group & & $\begin{array}{l}398.08 \\
( \pm 579.03)\end{array}$ & $t: 4.90$ \\
- Non-CRNA group & & $\begin{array}{l}80.25 \\
( \pm 229.11)\end{array}$ & $\begin{array}{l}p<0.001 \\
d: 0.72\end{array}$ \\
$\begin{array}{l}\text { Drug insurance } \\
\text { availability }\end{array}$ & $144(92.2 \%)$ & \\
- CRNA group & & $4(6.7 \%)$ & $\begin{array}{l}X^{2}: 1.07 \\
\text { - Non-CRNA group }\end{array}$ \\
& & $12(1.1 \%)$ & $p: 0.29$ \\
& & & \\
Additional & 127.50 & & \\
healthcare costs & $(25.00$, & & \\
& $378.75)$ & & \\
- CRNA group & & 673.81 & \\
& & $( \pm 987.02)$ & \\
- Non-CRNA group & & 241.46 & $p<0.001$ \\
& & $( \pm 392.71)$ & $d: 0.57$
\end{tabular}

$d$ indicates effect size for $t$-tests while $V$ indicates Cramer's $V$ for chisquare tests

${ }^{\mathrm{a}}$ This indicates median and interquartile ranges

expenditure of $\$ 405$ on additional healthcare needs increased the risk of facing CRNA among individuals with SCIs by $50 \%$.

Please note that these estimates were controlled for the province in order to account for the variability among provincial drug programs in Canada [6]. As the medication costs among our sample were rightly skewed, we tested for its nonlinear effects (if any) on CNRA through stratification, to ensure that the linearity assumption in regression modeling is not violated. We tested the final model for any confounding or potential interactions between the variables. The sex variable acted as a confounder as it was related to both our outcome variable (CRNA) and one of the main variables (medication costs). We also ran residual and influential diagnostics to find out any potential outliers that could affect our estimates. When model accuracy was calculated before and after removing influential observations, no significant improvement in the accuracy was found. Therefore, those observations were not removed from the analyses.

\section{Discussion}

This study is among the initial studies in Canada that explore the phenomenon of CRNA within the context of an SCI. Findings suggest the following: 
Table 4 Factors associated with CRNA in the study sample of community-dwelling persons with spinal cord injury $(n=160)$.

\begin{tabular}{llllllll}
\hline Independent factors & B & S.E. & Wald & Sig. & OR & \multicolumn{2}{l}{$\begin{array}{l}\text { 95\% C. } \\
\text { I. for OR }\end{array}$} \\
\hline Monthly expenditure on drugs $=\$ 50$ & 0.005 & 0.001 & 13.321 & 0.000 & $1.28^{\mathrm{a}}$ & 1.26 & 1.28 \\
Additional healthcare cost $=\$ 50$ & 0.001 & 0.001 & 4.621 & 0.032 & $1.05^{\mathrm{b}}$ & 1.04 & 1.06 \\
Females & 1.132 & 0.420 & 7.261 & 0.007 & 3.103 & 1.362 & 7.071 \\
Constant & -2.988 & 0.541 & 30.495 & 0.000 & 0.050 & & \\
\hline
\end{tabular}

OR odds ratio (adjusted), correct prediction: 79.4\%, df: 1, Hosmer and Lemeshow goodness-of-fit test $\chi^{2}$ : 8.716, df: 8, $p$ : 0.367, $-2 \log$ likelihood: 156.332 , Cox and Snell $R^{2}: 0.288$, Nagelkerke $R^{2}: 0.393$, results are adjusted for province

${ }^{\text {a }}$ This OR represents the increase in risk of facing CRNA with every $\$ 50$ increase in monthly expenditure on prescription medications

${ }^{\mathrm{b}}$ This OR represents the increase in risk of facing CRNA with every $\$ 50$ increase in additional healthcare costs per month
- Individuals with SCIs used between five and eight medications concurrently and spent a median of $\$ 49$ per month (or \$2058/year) on prescribed medications.

- Although $90 \%$ of participants had some form of drug insurance, $37 \%$ reported CRNA.

- Opioids, antidepressants, and drugs for genitourinary and muscular spasms were most likely to be forgone due to costs.

- Sex, monthly drug expenditure, and monthly additional healthcare costs were significantly associated with CRNA.

International research has shown that annual household out-of-pocket spending over $\$ 500$ a year perpetuates the risk of underusing medicines due to cost [20]. This partially explains why the prevalence of CRNA among people with SCIs was found dramatically higher $(37 \%)$ than that is reported for the general population (8-10\%) and comparable to other vulnerable populations in Canada (36\%) [21]. We also noted that out-of-pocket costs paid by the participants highly varied, suggesting that some people paid far more than the average while others paid far less. Two possible reasons can explain this. First, the variability in medication needs depending on one's age, and health status may have led individuals with an SCI to differential use of medications. Second, the differences in the drug insurance coverage within people with SCIs may have caused them to bear different costs for similar medication needs. The sample of this study varied in terms of age, income, employment, and province they lived in. The differences in these characteristics might have affected their drug insurance arrangements and hence their expenditure on drugs.

With respect to the type of medications, our study found that medications generally prescribed for pain, mental health conditions, and muscular and urinary spasms were most likely to be forgone due to cost. A recent national study in Canada also found that medications for mental health conditions were most commonly reported for CRNA
[8]. However, it must be noted that we could not identify specific medications that had a higher cost burden or prevalence of nonadherence for our participants. This was because medications that had restricted coverage and high costs for some people had no such implications for others, which affected patients' adherence decisions for those medications.

Another notable finding of this study was that people with SCIs faced CRNA despite having drug insurance and in some cases, more than one type of drug insurance. This finding can be explained by many possible reasons. First, several of these plans involve income-based deductibles (even for those with disabilities), which may be difficult to meet and have posed a financial burden on the individuals. Income-based deductibles have been demonstrated to lead to a reduction in overall drug use and costs, especially for low-income and vulnerable populations [22]. A second possible explanation of this finding is the heterogeneity in the extent of drug coverage and cost-sharing arrangements provided under public versus private health insurance plans [23, 24]. Previous research in Canada has shown that people who lack private drug insurance are more likely to face CRNA [25]. Of $70 \%$ of our sample who had public drug benefits, only $30 \%$ had additional drug coverage that private health insurance offers. The premiums and copayments associated with private health insurance plans are often high that may have deterred individuals with an SCI to have them. Another additional explanation for this finding can be that even a low deductible associated with public drug plans were difficult to manage for some people with SCIs. This may be especially true for people who are $<65$ years and have low-income with high additional healthcare costs. These costs may have posed an additional burden in such a way that they could not afford to pay even a small deductible.

We also found that the burden of additional healthcare costs directly influenced the ability of individuals with SCIs to afford medications. This finding partly explains the 
differences in the barriers faced by people with disabilities as compared to the general population [26]. It is important to note here that the additional healthcare costs that were considered for this study comprised costs for catheters, wheelchairs, special diet, or skincare supplies. These costs did not include cost for over-the-counter medications, home modifications, vehicular adaptations, attendant care, and cost of other rehabilitation services that people with SCIs may need. If these extra costs of living are accounted, the barriers to pay for medications may become even worse. Recent findings by Persaud et al. [27] and Goldsmith et al. [28] also indicate that there is a strong connection between financial burdens for medicines and other household needs, including other health expenditures.

It was also noteworthy that females were found to face a significantly higher risk for CRNA. This can be attributed to the fact that women are generally less likely than men to be employed, which affects their income and access to employer-based health insurance [29]. This finding aligns with the previous research that has shown that women with disabilities have the worst access to healthcare, including ability to afford medications from any other group such as men with and without disabilities and women without disabilities [30].

\section{Study limitations}

As our study adopted a cross-sectional approach, it was not possible to capture how medication use, cost, or nonadherence changed among study participants over a period of time. The study is based on self-reported data that cannot be validated by external data. Participants may underestimate or overestimate the medication costs and consequently lead to potential information bias. The recruitment process depended on voluntary participation; therefore just like all surveys, our survey was also limited by its reliance on participants to provide accurate and honest responses. A 12-month retrospective time period to determine the occurrence of CRNA might be unequally estimated by participants compared to a more recent situation, which may introduce recall bias. Lastly, due to the relatively small sample size, it is difficult to know whether our sample was reflective of the target population despite similarities in some key demographic characteristics.

\section{Future directions}

Future research can be directed towards understanding the impact of multiplicity and complexity of drug insurance arrangements on patients' adherence. Health services and policy researchers should also focus on the development and promotion of tools that inform cost-sensitive prescribing. These guides may help clinicians to choose between therapeutically similar medications with similar anticipated outcomes but often substantially higher prices. This study has implications for the proposed plans for a "universal" pharmacare program in Canada by the federal advisory council. This study suggests that it may be an appropriate policy solution given evidence of patients falling through the cracks of the complex private/public system of Canada, even if $92 \%$ of them are apparently "covered" by a private or public plan of some kind.

\section{Data archiving}

The datasets generated and analyzed during the current study are available from the corresponding author on reasonable request.

Acknowledgements We would like to acknowledge the support of various organizations, including the Rick Hansen Institute, SCI Canada, Canadian Spinal Research Organization, and various others for helping us with the recruitment for the study.

Funding This research was conducted as part of the doctoral thesis work of SG. Her work is supported through the doctoral studentship awarded by Queen's University and Mark S Lodge Fund in an SCI research. SJTG is supported by the Canadian Institutes for Health Research Embedded Clinician Scientist Salary Award on Transitions in Care. The funders had no role in the design of the study; in the collection, analyses, or interpretation of data; in the writing of the manuscript, or in the decision to publish the results.

Author contributions The paper was prepared by SG, who also collected and analyzed data. MAM supervised SG and provided substantial contributions to study conception and design and data analysis and interpretation. SJTG and KS are the subject experts and senior authors who contributed in revising the article critically for important intellectual content. All authors contributed toward data analysis, drafting, and revising the paper and agree to be accountable for all aspects of the work.

\section{Compliance with ethical standards}

Conflict of interest The authors declare that they have no conflict of interest.

Ethical statement Ethical clearance for the study was obtained from the Health Sciences Research Ethics Board (HSREB\#912502) of Queen's University. We certify that all applicable institutional regulations concerning the ethical use of human volunteers were followed during the course of this research.

Publisher's note Springer Nature remains neutral with regard to jurisdictional claims in published maps and institutional affiliations.

\section{References}

1. McDaid D, Park A, Gall A, Purcell M, Bacon M. Understanding and modelling the economic impact of spinal cord injuries in the United Kingdom. Spinal cord. 2019;57:778-88. 
2. Krueger H, Noonan VK, Trenaman LM, Joshi P, Rivers CS. The economic burden of traumatic spinal cord injury in Canada. Chronic Dis Inj Can. 2013;33:113-22.

3. Rouleau P, Guertin PA. Traumatic and nontraumatic spinal-cordinjured patients in Quebec, Canada. Part 3: pharmacological characteristics. Spinal Cord. 2011;49:186-95. https://doi.org/10. 1038/sc.2010.70.

4. Krause JS, Saunders LL. Risk of hospitalizations after spinal cord injury: relationship with biographical, injury, educational, and behavioral factors. Spinal Cord. 2009;47:692-97.

5. Canadian Institute for Health Information. National health expenditures database, 1975 to 2018, Table G.14.1. Ottawa, ON: Canadian Institute for Health Information; 2018.

6. Campbell DJT, Manns BJ, Soril LJJ, Clement F. Comparison of Canadian public medication insurance plans and the impact on out-of-pocket costs. CMAJ Open. 2017;5:E808-E813.

7. A Ontario Citizens' Council. A Report of the Ontario Citizens' Council: Private Drug Insurance in Ontario. 2012. http://www.hea lth.gov.on.ca/en/public/programs/drugs/councils/docs/report_ private_drug_insurance_ontario.pdf.

8. Law MR, Cheng L, Kolhatkar A, Goldsmith LJ, Morgan SG, Holbrook AM, et al. The consequences of patient charges for prescription drugs in Canada: a cross-sectional survey. CMAJ Open. 2018;6:E63-E70.

9. Hennessy D, Sanmartin C, Ronksley P, Weaver R, Campbell D, Manns B. Out-of-pocket spending on drugs and pharmaceutical products and cost-related prescription nonadherence among Canadians with chronic disease. Health Rep. 2016;27:3-8.

10. Campbell DJ, King-Shier K, Hemmelgarn BR, Sanmartin C, Ronksley PE, Weaver RG. Self-reported financial barriers to care among patients with cardiovascular-related chronic conditions. Health Rep. 2014;25:3-12.

11. Guilcher SJT, Hogan ME, Calzavara A, Hitzig SL, Patel T, Packer T, et al. Prescription drug claims following a traumatic spinal cord injury for older adults: a retrospective population-based study in Ontario, Canada. Spinal Cord. 2018;56:1059-68.

12. Kitzman P, Cecil D, Kolpek JH. The risks of polypharmacy following spinal cord injury. J Spinal Cord Med. 2016;40:1-7.

13. Lavrakas P. Encyclopedia of survey research methods. Thousand Oaks, California: SAGE Publications Inc; 2008. http://methods.sa gepub.com/reference/encyclopedia-of-survey-research-methods

14. Gupta S. Ethical issues in designing internet-based research: recommendations for good practice. J Res Pract. 2017;13:1-14.

15. Farry A, Baxter D. The incidence and prevalence of spinal cord injury in Canada: overview and estimates based on current evidence. Rick Hansen Institue and Urban Futures; Ontario, Canada; 2010.

16. Charan J, Biswas T. How to calculate sample size for different study designs in medical research? Indian J Psychol Med. 2013;35:121.
17. Noreau L, Noonan VK, Cobb J, Leblond J, Dumont FS. Spinal cord injury community survey: understanding the needs of Canadians with SCI. Top Spinal Cord Inj Rehabil. 2014;20:265-76.

18. World Health Organization. Guidelines for ATC classification and DDD assignment 2013. WHO collaborating centre; Ontario, Canada; 2013;1-284.

19. Wishart DS, Feunang YD, Guo AC, Lo EJ, Marcu A, Grant JR, et al. DrugBank 5.0: a major update to the DrugBank database for 2018. Nucleic Acids Res . 2018;46(D1):D1074-82.

20. Kemp A, Roughead E, Preen D, Glover J, Semmens J. Determinants of self-reported medicine underuse due to cost: a comparison of seven countries. J Health Serv Res Policy. 2010;15:106-14.

21. Gupta S, Mccoll MA, Guilcher SJ, Smith K. Cost-related nonadherence to prescription medications in Canada: a scoping review. Patient Prefer Adherence 2018;12:1699-715.

22. Law MR, Cheng L, Worthington H, Majumdar SR, McGrail KM, Chan F, et al. Impact of a household-level deductible on prescription drug use among lower-income adults: a quasiexperimental study. CMAJ Open. 2019;7:E167-E173.

23. Baicker K, Goldman D. Patient cost-sharing and healthcare spending growth. J Econ Perspect. 2011;25:47-68.

24. McKillop CN, Waters TM, Kaplan CM, Kaplan EK, Thompson MP, Graetz I. Three years in-changing plan features in the US health insurance marketplace. BMC Health Serv Res. 2018; 18:450-14.

25. Lee A, Morgan S. Cost-related nonadherence to prescribed medicines among older Canadians in 2014: a cross-sectional analysis of a telephone survey. Can Med Assoc J Open. 2017;5: E40-E44.

26. Gupta S, McColl MA, Smith K, Guilcher SJT. An adapted model to understand cost-related nonadherence to medications. J Disabil Policy Stud. 2019 https://doi.org/10.1177/1044207319868779.

27. Persaud N, Bedard M, Boozary AS, Glazier RH, Gomes T, Hwang SW, et al. Effect on treatment adherence of distributing essential medicines at no charge: the CLEAN meds randomized clinical trial. JAMA Intern Med. 2019 https://doi.org/10.1001/ jamainternmed.2019.4472.

28. Goldsmith LJ, Kolhatkar A, Popowich D, Holbrook AM, Morgan SG, Law MR. Understanding the patient experience of costrelated nonadherence to prescription medications through typology development and application. Soc Sci Med. 2017;194:51-9.

29. Pelletier R, Patterson M, Moyser M. The gender wage gap in Canada: 1998 to 2018. Labour Statistics-Stats; Ontario, Canada; 2019.

30. Sakellariou D, Rotarou ES. Access to healthcare for men and women with disabilities in the UK: secondary analysis of crosssectional data. BMJ Open. 2017;7:e016614. 